\title{
Histological Evaluation of Guided Bone Regeneration in Osseous Defects Using A Novel Non-Resorbable Membrane
}

\author{
Mohamed Abdelhamid Ahmed Ali ${ }^{1}$, Diana Mostafa ${ }^{2 *}$ (D) \\ ${ }^{1}$ Department of Oral Surgery and Maxillofacial, Faculty of Dentistry, Alexandria University, Alexandria, Egypt; ${ }^{2}$ Department of \\ Periodontology and Oral Medicine, Faculty of Dentistry, Alexandria University, Alexandria, Egypt.
}

\begin{abstract}
\end{abstract}
Edited by: Filip Konesk Citation: Ali MAA, Mostafa D. Histological Evaluation of Guided Bone Regeneration in Osseous Defects Using $A$ Novel Non-Resorbable Membrane. Open Access Maced Med Sci. 2022 Jan 26; 10(D):83-90 https://doi.org/10.3889/oamjms.2022.8262 Keywords: Guided bone regeneration; Non-resorbable arrier; Propylene membrane; Guided tissue regeneration "Correspondence: Diana Mostafa, Diana Mostafa, of Dentistry Alexandria University Faculty E-mail: dr.dianamostafa@gmail.com Received: 15-Dec-2021 Revised: 09-Jan-2022 Accepted: 16-Jan-2022
Copyright: $\odot 2022$ Mohamed Abdelhamid Ahmed Ali, Funding: This research did not receive any specific grant from funding agencies in the public, commercial, or Competing Interests: The authors have der-profit sectors Competing Interests: The auhors have declared that $n$ competing interests exist Open Access: This is an opeative Commons AtributionNonCommercial 4.0 International License (CC BY-NC 4.0)

\section{Introduction}

The first presentation of a membrane giving evidence that guided tissue regeneration (GTR) could enhance regeneration of periodontal tissues was done by Nyman et al. [1]. Originally, Dahlin et al. [2] used this procedure to regenerate bone in an osseous defect to exhibit the concept of "osteopromotion". Later, Buser et al. [3] presented the term "guided bone regeneration (GBR)", the application of a physical barrier between the connective tissue and the alveolar defect to improve healing of the bone by prohibiting the fastergrowing non-bony fibrous tissues from interfering with the bone wound, consequently it preserves a solitude area for optimal bone formation. These techniques have been performed using barrier membranes in clinical dentistry to enhance bone formation in osseous defects, ridge preservation and reconstruction before implant placement and bone augmentation at failing implants [4].

GBR is targeting the generation of a single tissue, which is bone, while GTR strives to regenerate multiple tissues in a complex relationship, including the reconstruction of periodontal ligaments, collagen fibers inserted in new cementum and newly regenerated bone. In addition, the regeneration of tissues in GTR happens in a hostile healing nature because of the intimacy of roots contaminated by local factors such as plaque, calculus and toxins, in contrary to the situation in GBR procedures, the GBR is more predictable than GTR as a procedure for new bone formation [5].

Although the placement of the barrier on the bone graft is expected to avoid the remodeling of the bone with consequent resorption of the grafted bone, the barrier membrane may increase the predictableness of the augmentation procedure [6]. Controversies involved the placement of barriers to cover the augmented site or not [6]. However, barrier membranes shield the adjacent soft tissues from obstructing the regeneration of bone, increase the mechanical stability of the bone graft and reduce the micro-mobility [3].

Broadly, membranes are categorized as non-resorbable membranes and absorbable membranes. Non-resorbable membranes such as expanded polytetrafluoroethylene, High-density polytetrafluoroethylene, titanium mesh, retain their build and form in the tissues which are used in surgical procedures that require a great quantity of grafted material and an additional surgery for their removal 
is a must [7]. While resorbable membranes don't require additional surgery for their removal such as collagen, acellular dermal matrix, dura matter, chitosan, periosteum and calcium sulfate [7]. Although absorbable membranes prevent surgical re-entry for their removal, most of them degrade before the completion of bone formation and sometimes their degradation process is associated with inflammation [8]. Another disadvantage is the lack of stiffness which may cause the membrane to collapse in the defect area [9]. In contrast, the non-resorbable barriers have the ability to sustain a separation of tissues over an extended time, but if they become exposed, they will not heal spontaneously and become bacterial contaminated which may lead to wound infection [10]. Despite the considerable number of studies that have been directed towards the development of a new biomaterial with more advantages and fewer disadvantages for bone regeneration, the cost and surgical approach difficulties are still the main obstacles for barrier applications in GBR or GTR [5].

However, polypropylene is a synthetic biomaterial that is a bioinert and thermoplastic polymer, that is used in broad medical applications involving vascular graft prosthesis, heart patch and membrane oxygenator. Its use in dentistry as a barrier membrane covering the bony defect for osseous regeneration is still unverified. In our study, we demonstrated the effect of a novel non-resorbable polypropylene barrier in GBR in dog models considering its availability, low cost and biocompatibility.

\section{Aim of the work}

The purpose of our study was to evaluate histologically the osseous formation process in experimental mandibular osseous defects in dog models using a synthetic, customized, inexpensive non-resorbable polypropylene membrane with bone graft material in comparison with using the bone graft material only.

\section{Materials and Methods}

After the approval of the ethical board of Alexandria University on the study protocol, we followed the ethical guidelines for the care and use of ten healthy male mongrel dogs as documented by veterinarian reports. They were maintained under the same dietary and environmental conditions in the animal house at the Physiology Department, Faculty of Medicine, Alexandria University. NIH guidelines for the care and use of laboratory animals have been observed.

\section{Materials}

\section{Bio-Oss graft}

(Geistlich

Biomaterials,

Wolhusen, Switzerland): a natural, non-antigenic, spongious bone substitute (the mineral portion of bovine bone) which was provided in the granular form, with particle size 1-2 $\mathrm{mm}$. It was moistened with blood or physiological saline solution.

\section{The novel plastic membrane}

A flat plastic membrane with a dome shape elevation in the middle and a movable crescent shape portion of the upper part of the elevation to allow loading of the Bio-Oss after fixation of the membrane while at the peripheries there were two small hollows for screws as shown in Figure 1. The membrane was a customized barrier made by dental material specialists in the lab of the Faculty of Dentistry, Alexandria University, Egypt. The pure low-density polypropylene resin powder was extruded using heat and rolling technique into $0.5 \mathrm{~mm}$ thick sheets using an industrial extruder production line. The produced sheets were cut into $2 \mathrm{~cm} \times 2 \mathrm{~cm}$ sheets and inserted into sterilization envelopes. The sealed envelopes were received gamma-ray sterilization to ensure a completely sterile environment. The produced sheets were tested under laboratory conditions to assess density, tear strength, and permeability to body fluids.

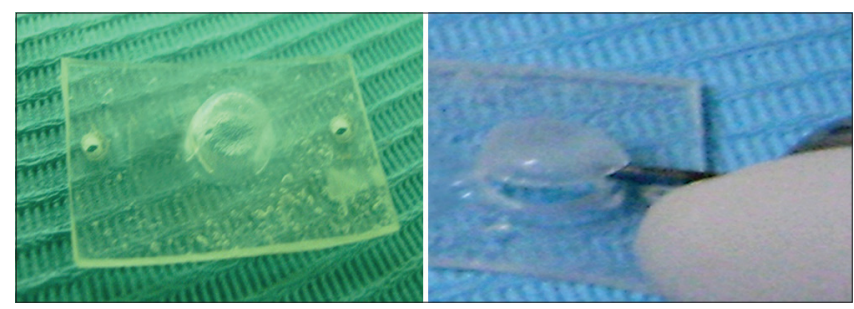

Figure 1: The novel plastic membrane with a dome shape elevation in the middle, a movable crescent shape portion is present to allow loading of the Bio-Oss after fixation of the membrane

\section{Surgical procedure}

\section{Animal preparation}

All dogs received an antibiotic (Enrofloxacin $10 \%$ ) $0.6 \mathrm{mg} / \mathrm{kg}$ body weight before the surgical procedure. Animals were injected with Xylazine $(1 \mathrm{mg} / \mathrm{kg}$ body weight) intramuscularly as a pre-anesthetic agent. Then, they were generally anesthetized with intramuscular induction of ketamine hydrochloride (10 $\mathrm{mg} / \mathrm{kg}$ body weight).

\section{Surgical operation}

First, hair shaving was performed on the operating sites. The surgical field was swabbed with $2 \%$ alcoholic iodine solution before the operation. 
A submandibular skin incision on each side of the mandible ( 2 inches in length left and right) was done on the inferior border of the mandible using Bard Parker scalpel handle no.3 and disposable blade No.10. The periosteum was incised at the lower border of the mandible and reflected buccally and lingually utilizing the periosteal elevator to elevate the flaps exposing the bone (Figure 2a). A bone defect of $1 \mathrm{~cm}$ in diameter with $1 \mathrm{~cm}$ depth was created using a trephine bur apical to a premolar area on each side (Figure $2 b$ ). In the left side of each dog (Bio-Oss group), the osseous defect was filled with the bone graft with $1 \mathrm{~cm}$ height (Figure 2c). While on the right side of each dog (Bio-OSS and membrane group), fixation of the membrane was done using two mini-screws (Figure 2d). Then, grafting material was applied to the bone defect through the upper movable portion in the dome-shaped elevation of the membrane. The osseous defect was filled with a bone graft with a $1 \mathrm{~cm}$ height (Figure 2e-f). Both periosteal flaps were repositioned and were closed in layers using a 4/0 vicryl suture.

\section{Post-operative phase and follow-up periods}

Following the operation, each animal completed the antibiotic course (Enrofloxacin 10\%) 3 times/day for 5 days. Cataflam injections were given as analgesic and anti-inflammatory medicine every $8 \mathrm{~h}$ for 3 days. The dogs were transported to clean cages to observe any signs of infection, wound dehiscence, or graft rejection.

The animals were sacrificed at different intervals postoperatively at week $3,6,9$, and 12 by anesthesia of an overdose of Ketamine hydrochloride. Three dogs were sacrificed in each interval of week 3 and 12 , while two dogs were sacrificed in each interval of week 6 and 9.

\section{Histological study}

The areas of the surgical bony defect on the right and left sides of the mandible were dissected out and removed as blocks. However, all divisions were provided as decalcified sections except sections of a dog that was sacrificed after 3 weeks. Its sections were prepared as calcified divisions for further examination of the difference in bone formation in both groups.

\section{Preparation of decalcified sections}

First, the sections were instantly fixed in $10 \%$ neutral buffered formalin for a minimum of 2 weeks and then washed overnight in running water to remove the redundant fixation solution. Second, the specimens were decalcified in $5 \%$ trichloracetic acid, and then were left under running water for at least $24 \mathrm{~h}$ to eliminate all the acid. They were progressively dehydrated in ascending concentrations of alcohol (50\%, 70\%, 90\% and 100\%). Then, they were removed from the xylene and were put in a melted paraffin plate in a constant temperature oven $\left(60^{\circ} \mathrm{C}\right.$ for 2-3 h).

When the specimens were completely infiltrated, they were removed and inserted in the center of a paraffin box, then the paraffin blocks were

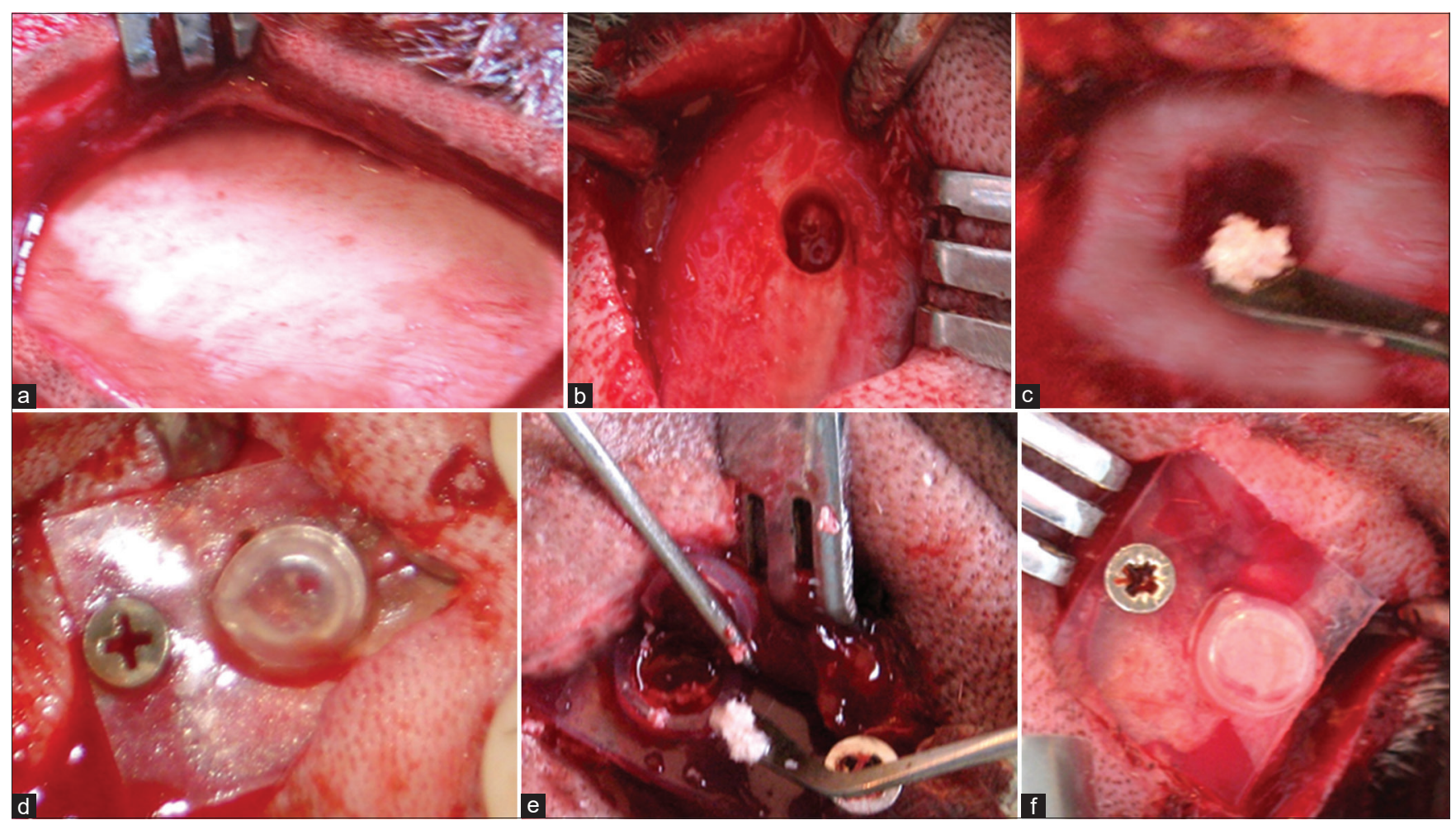

Figure 2: (a-f) The steps of the surgical operation of both sides of a dog represent group I and group II 
serially segmented to $5 \mu$ and sections were set on slides and placed in a constant temperature oven. The serial sections of every sample were stained with 2 stains including hematoxylin and eosin stain for general evaluation, which resulting deep blue nuclei and pink cytoplasm, collagen and bone. The second stain was trichrome stain which was utilized to detect the collagen fibers and the formation of osteoid tissues, resulting in green collagen, blue-grey nuclei and red cytoplasm and RBCs. Finally, the assessment of bone formation in the bony defects was done under a light microscope.

\section{Preparation of calcified sections}

The sections which included the grafting material and membrane were instantly set in $4 \%$ buffered formaldehyde for a week. Then, they were dehydrated by ascending alcohol concentrations $(50 \%, 70 \%, 90 \%$ and $100 \%)$. Then, sections were defatted in Xylene and after that, they were inserted in a chemically polymerized Methyl Metha-acrylate resin. Subsequently, they were cut, grinded, and polished where at least four middle sections were obtained for each specimen. Serial segments of about $0.3 \mathrm{~mm}$ were cut for the stereomicroscopy and were stained by Stevanl's blue and Van Geison's stains. Imaging and analysis of sections were done utilizing light stereomicroscopy and a high-resolution camera.

\section{Results}

\section{Clinical evaluation}

The steps of flap elevation and repositioning were carried out with no significant problems. After the surgical operations, some sites in both groups showed mild clinical edema but with no observed infection. The dogs were fed regularly with no complications. There was no abnormal immunologic response at any site of the operations in both study groups. Therefore, the clinical results revealed neither an inflammatory reaction nor graft rejection.

\section{Histological results of the decalcified sections stained by H\&E stain}

After 3 weeks, the results of group I (BioOss) showed a very minimal amount of new bone which appeared as thin islands of woven bone around the border of the defect (Figure 3a). There was no evidence of new bone regeneration in the defect center. In addition, the cavity was filled with fibro-vascular connective tissue which was formed of dense collagen fibers and many newly formed blood vessels with fibroblast cells in between (Figure $3 b$ ). The regenerated woven bone at the margins was formed of osteoid tissue containing many disorganized osteocytes and lined by a layer of osteoblast cells (Figures $3 c$ and d). This osteoid island varied in thickness and was seen to be attached to the old bone at some points (Figures 3a, $b$ and $d)$. While in other areas, the discrete islands were detached from the original bone by loose connective tissue (Figure 3c).

While the results of Group II (Bio-Oss and the novel membrane) showed regenerated bone under the novel membrane which was composed mainly of immature bone in a greater amount when compared with Group I (Figure 3d). Areas of union between the regenerated new bone and original bone were clearly seen with less amount of loose connective tissue between the two edges of bone (Figure 4). Furthermore, the osteoid tissue was formed in the center of the defect as interconnected large areas or small discrete islands enclosing osteocytes and lined by osteoblasts. This central new bone formation was surrounded by dense fibrovascular connective tissue (Figure 5).

\section{Histological results of the calcified sections (mineralized tissue section) stained by Stevenel's blue \& van Gieson's stain}

After 3 weeks, the results of Group I (Bio-Oss) showed a very minimal amount of newly formed bone which appeared as scattered islands of newly formed bone around the periphery of the defect area (Figure 6). While in Group II (Bio-Oss and the novel membrane), the regenerated bone under the novel membrane was formed in a greater amount when compared with Group I (Figure 7). The difference in color between the fully mineralized new bone with blue color and less mineralized

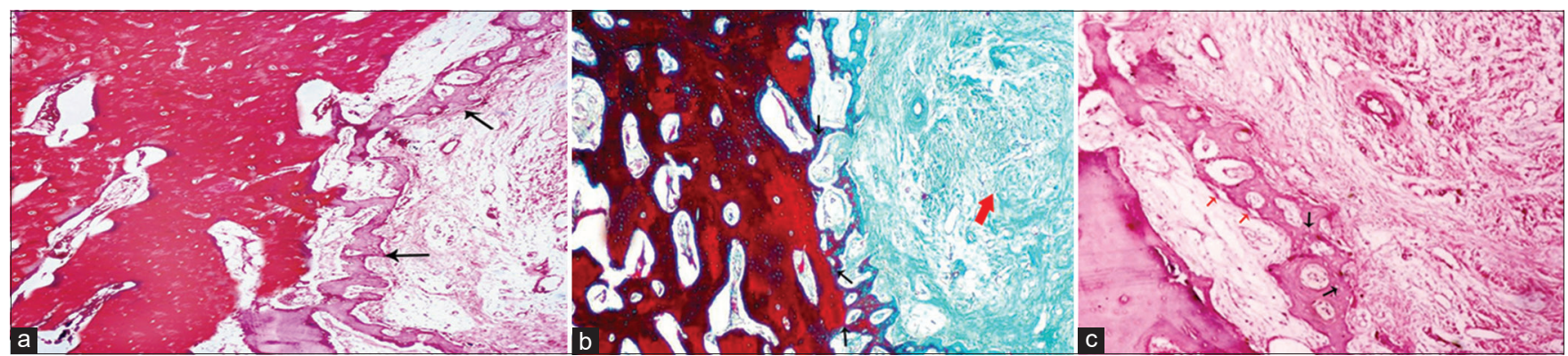

Figure 3: (a-c) The surgical defect of group I (Bio-Oss alone) after 3 weeks (H\&E stain; original magnification $\times$ 40) 


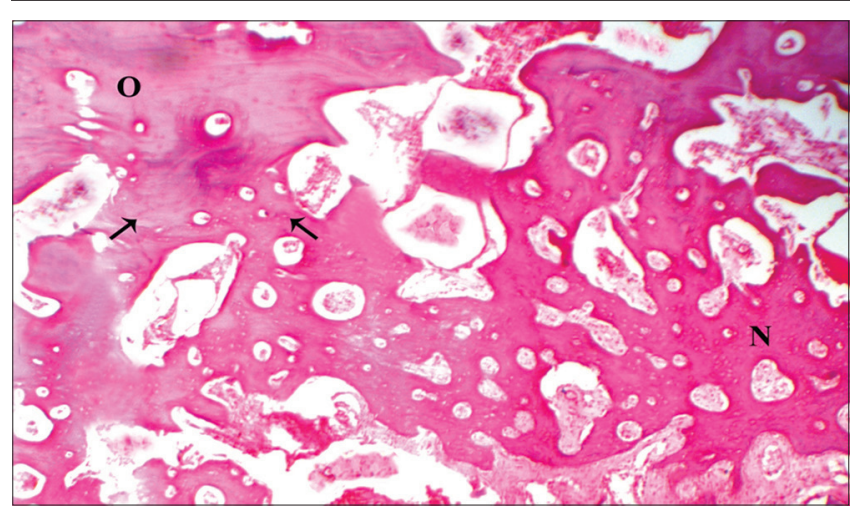

Figure 4: After 3 weeks in Group II (BioOss and the novel membrane), thick areas of immature bone at the periphery of the defect and areas of union (black arrows) between original (O) and regenerated new bone $(N)$ were observed. (H\&E stain; original magnification $\times 40$ )

new bone with the brown color indicated the presence of different stages of bone regeneration (Figure 7).

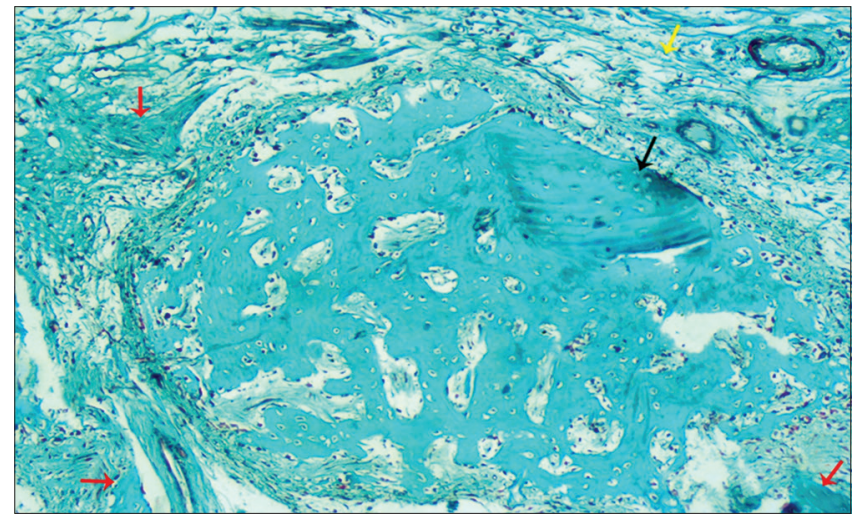

Figure 5: In Group II (BioOss and the novel membrane) after 3 weeks, the new bone formation in the center of the defect formed large interconnected bone trabeculae (black arrow) and discrete small islands (red arrows ) containing many entrapped osteocytes, lined by osteoblasts were observed. Fibrovascular connective tissue surrounded the woven bone (yellow arrows) (Trichrome stain; original magnification $\times 100$ )

The new osseous formation occurred under the whole surface of the membrane, regardless of the presence or absence of bone graft, including the center and the peripheries of the defect (Figure 7).

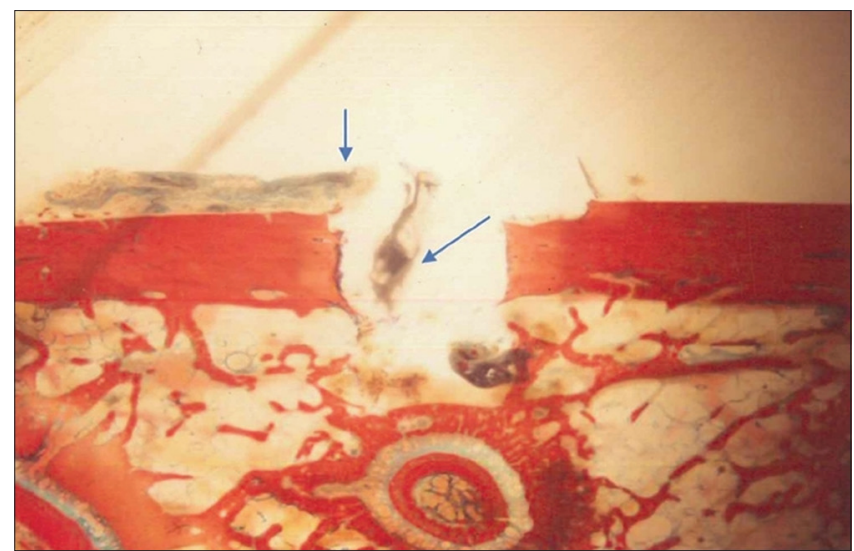

Figure 6: The under calcified ground Methyl Methacrylate section of the surgical bony defect in Group I (BioOss) after 3 weeks using Van Gesion\& Stevenl's blue stain which showed the newly formed bone on the host bone surface scattering in a few amount (blue arrow). (Original Magnification $\times 20$ )
At week 6, the results of Group I (Bio-Oss) revealed that there was a greater amount of new immature bone in comparison to Group I at 3 weeks. The new bone was limited to the walls of the defects only. The beginning of the formation of a few thin woven bones was seen beneath the immature regenerated bone.

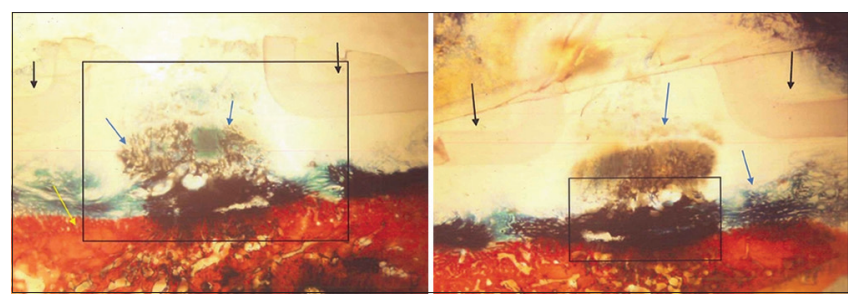

Figure 7: The undercalcified ground Methyl Methacrylate section of the surgical bony defect in Group II using BioOss and the Novel membrane after 3 weeks using Van Gesion\& Stevenl's blue stain. (Original Magnification $\times 20$ )

Fibrovascular tissues were still filling large areas of the defect. The union between regenerated bone and the original bone was clearly detected at some sites of the margins (Figure 8a). While in Group II (Bio-Oss and the novel membrane), the ongoing regenerated bone beneath the new membrane appeared dense and filled a great amount of the area of defect. Large areas of the formed immature bone were observed at the periphery with large marrow spaces between the trabeculae (Figure 8b).

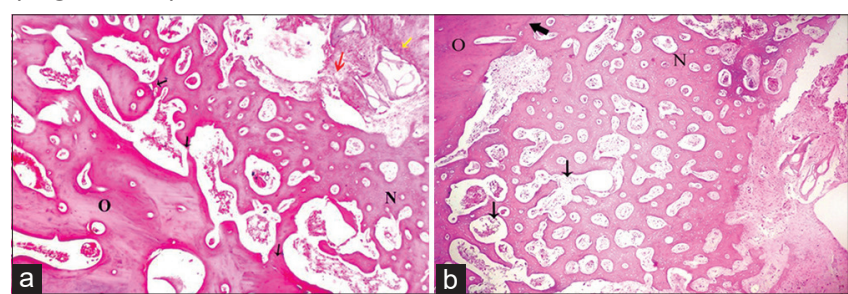

Figure 8: $(a$ and $b)$ : The surgical bony defect in both groups after 6 weeks (H\&E stain; original magnification $\times 40$ )

The union between the original and regenerated bone was still incomplete. Small areas of connective tissue were observed along the peripheral margin (Figure 8b). In the middle of the defect, the new bone formation was surrounded by a small amount of dense fibrovascular connective tissue. The regenerated bone was rimmed with osteoblasts as well as the wide marrow spaces. Osteocytes were seen embedded in the regenerated immature bone (Figure 9).

After 9 weeks, Group I (Bio-Oss) showed new bone in an incomplete union with the old original bone. The amount of new bone increased and

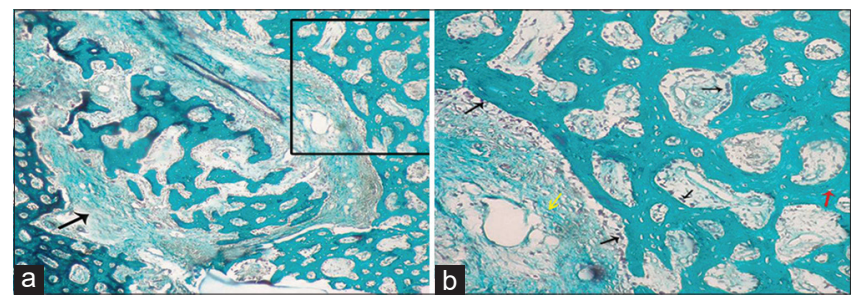

Figure 9: (a and b): The surgical bony defect in Group II (BioOss and the novel membrane), after 6 weeks showed (Trichrome stain, original magnification $\times 100$ ) 
projected downward toward the defect center bridging the fibrovascular connective tissue and enclosing large areas of it (Figure 10a). The regenerated bone consisted of wide spaces containing fibrous tissue and primary osteons with osteocytes. While in Group II (Bio-Oss and the novel membrane), the mature bone and regenerated bone could be hardly identified. The fibrous tissue at the margin of the defect between the original bone and the newly formed one was almost replaced by the regenerated bone (Figure 10b).

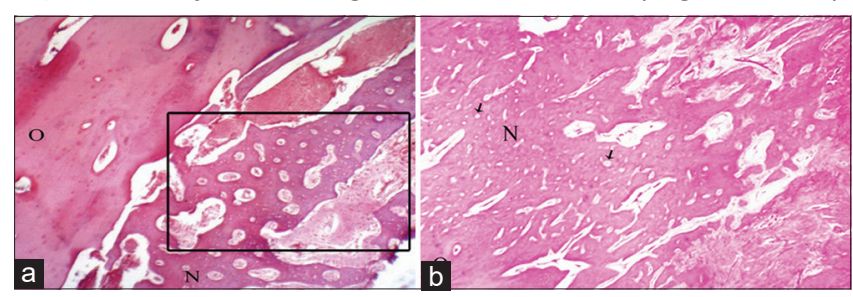

Figure 10: ( $a$ and b): The surgical bony defect in both groups after 9 weeks, (H\&E stain; original magnification $\times 100$ )

The formation of bone was enhanced as the amount of bone formed was greater in comparison with Group I (Figure 10). Histological signs of the beginning of bone maturation were observed. There was evidence of remodeling of the woven bone to new lamellar bone at the periphery while the recent and new bone showed immature wide spaces lined by osteoblasts as well as enclosing osteocytes in its matrix. The center of the defect showed woven bone trabeculae of different sizes and thicknesses scattered between the fibrovascular connective tissue, which filled only small areas (Figure 11).

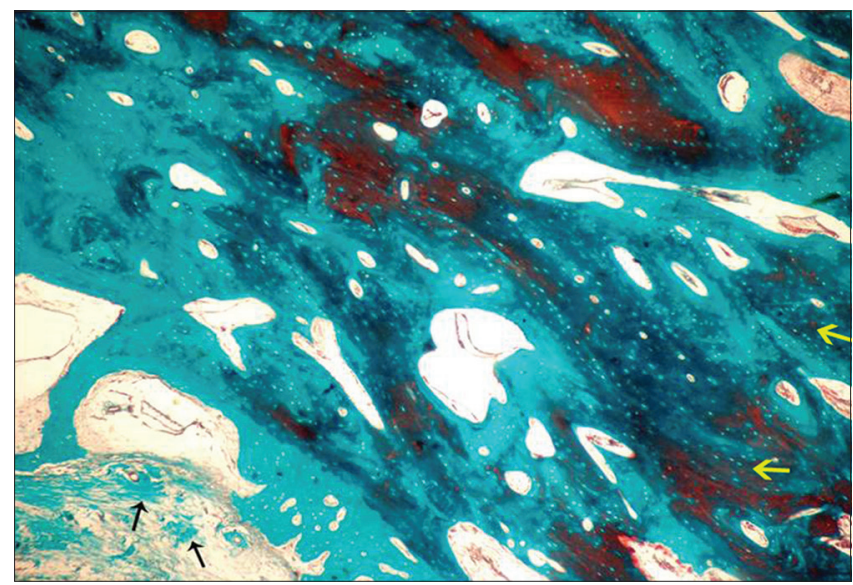

Figure 11: The surgical bony defect in Group II (BioOss and the novel membrane), after 9 weeks showed regenerated bone maturation toward the original bone (yellow arrows). The center is still filled with thick fibrovascular connective tissue and woven bone formation (black arrows). (Trichrome stain; original magnification $\times 40$ )

Twelve weeks postoperatively, Group I (BioOss) showed incomplete healing of the defect with bone. The fibrous connective tissue was still present in the center. The new bone adjacent to the margins of the original one exhibited lamellar structure and showed complete union with the original bone (Figure 12a). The regenerated bone toward the center formed new immature bone with wide spaces which were aligned

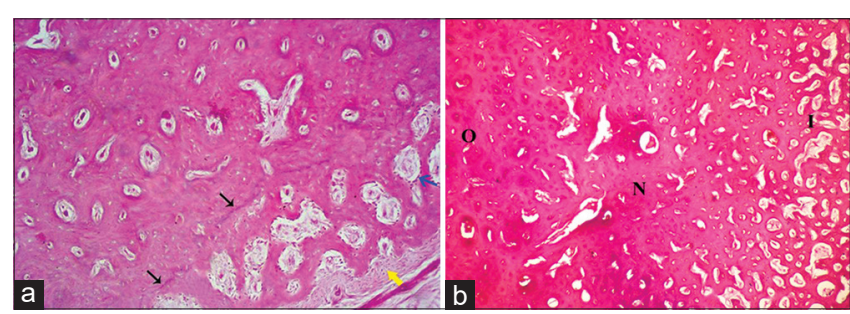

Figure 12: ( $a$ and b): The surgical bony defect in both groups after 12 weeks using H\&E stain (original magnification $\times 40$ )

with a layer of osteoblasts. Nearest this newly formed bone, woven interconnected trabeculae surrounding a connective tissue rich in fibers, cells and vessels in a condensed presentation (Figure 13a). While Group II (Bio-Oss and the novel membrane) showed the margins between the surrounding original bone and new bone disappeared (no clear border between their edges). The osseous defects were restored with new bone which was either mature or immature. The amount of new mature lamellar bone had increased adjacent to the original bone. This new bone showed tightly packed secondary osteons with the narrow lumen of the Haversian canals creating an organized bone matrix. The center of the defects was completely occupied with immature bone with wide marrow spaces and no dense fibrovascular tissue in the center (Figures 12b and 13b).

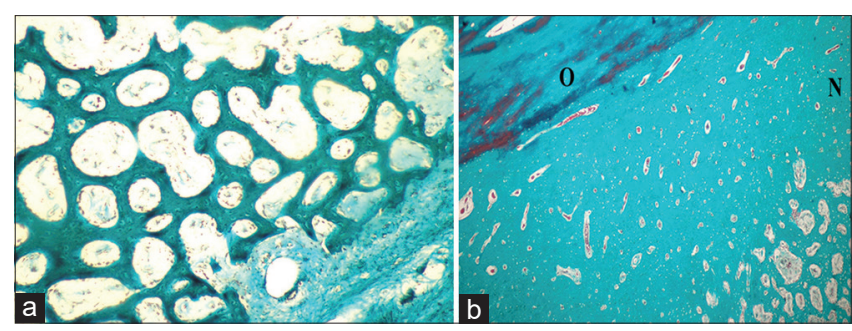

Figure 13: ( $a$ and b): The surgical defect in both groups after 12 weeks using trichrome stain (original magnification $\times 40$ )

\section{Discussion}

Although the advances in the membranes for treating bone defects, it is still a challenge to treat them. In this study, we used the novel membrane which is a plastic non-resorbable membrane of medical thermoplastic polymers, considering its availability, low cost and biocompatibility. We used it as a barrier to provide an isolated space around the osseous defects, discrete tissues during the healing process, hinder apical migration of the epithelium and protect the graft material in the defect [11]. Besides, we utilized a xenograft material (Bio-Oss) which is a deproteinized bovine bone mineral (DBBM) that has the ability to bond to the alveolar bone and act as a substitute for bone formation as it is characterized as osteoconductive material that increases the mineral content [12]. Although other studies [13], [14] used non-resorbable polypropylene barrier alone without 
bone graft material, they conducted good results with polypropylene membrane where the bone defects were filled with blood clots and new bone was formed.

Regarding the follow-up periods, it ranged from 3 to 12 weeks as the cycle of bone remodeling takes 12 weeks in dogs, different from rats (6 weeks) and humans (17 weeks) [13]. So that after 12 weeks, we could evaluate the bone remodeling between the two groups. However, in both groups, results provided histological evidence of new bone formation in intimate contact with host bone. This is due to the osteoconductive property of Bio-Oss as it acts as a scaffold for new bone formation and as a support for GBR as it is capable of becoming well vascularized and integrated with new host bone [15].

Furthermore, the formation of new bone in group I (Bio-Oss only) was less in the amount as compared with group II (Bio-Oss with the novel plastic membrane) at all different intervals from 3 to 12 weeks. This indicates that the novel membrane enhanced bone regeneration as well as its maturation. This is due to the principle of the technique which is compartmentalized wound healing, a space is formed by the application of the physical barrier where only angiogenic and osteogenic cells are permitted to proliferate in the wound area and compete with non-osteogenic soft tissue cells [16]. Furthermore, the bone graft material was homogenously stabilized by the novel membrane resulting in tissue integrity. In general, the osteoblastic differentiation was initiated within the $1^{\text {st }}$ weeks and intensified on the surfaces of new bone. This is maybe due to the Bio-Oss substitutes being totally integrated into a secondarily produced trabecular bone, developing complete bone organization of the defects [17].

Our results were in agreement with some investigational studies which used DBBM in the management of the osseous defects of peri-implant tissues. Their histologic findings concluded that DBBM displayed successful osteoconductive effects when it is in proximity to the newly formed bone [18]. Similar results were presented by many studies [19], [20] which supported the positive effect of DBBM when it is used in a grafting mixture to improve the stability of the augmented bone. Furthermore, Simion et al. [19] revealed that the GBR procedure of osseous defects surrounding titanium implants provides considerable alveolar bone augmentation. The results showed a larger amount of bone fill in the test group than in the controls.

These observations were in accordance with Schallhorn and Mclain [21] who suggested that bone regeneration was enhanced when the non-resorbable membrane was combined with the placement of demineralized freeze-dried bone allograft (DFDBA). Furthermore, our findings were corresponding to Anderegg et al. [22] who reported significantly greater bone regeneration when GBR procedures were done with the non-resorbable membrane (PTEF) and DFDBA compared to PTEF membranes alone.
However, our findings were in contrast to Caffesse et al. [23] and Meldo et al. [24] who found that the amount of bone was increased in defects treated with non-resorbable membrane PTEF alone without bone graft. Furthermore, our observations were in disagreement with Becker et al. [25] who found that the bone regeneration when placing DFDBA was highly variable and the efficacy of non-resorbable membranes was not significant where there was no evidence of new bone regeneration. These contradicting results may be due to the use of a different membrane in our study, which was the novel membrane that has some properties better than the PTEF membrane including the enhancement of healing and bone regeneration [13].

\section{Conclusion}

Within the context of our research, we concluded that the treated sites of osseous defects with Bio-Oss and the novel non-resorbable membrane showed histologically higher bone formation relative to the Bio-Oss alone. In addition, the novel non-resorbable membrane would provide a safe, biocompatible and costeffective osseous regeneration therapy in hard tissue engineering. Although our experimental study revealed the positive effect of polypropylene membrane in the GBR procedure, this study can be considered as baseline data for the novel non-resorbable membrane. However, there is a need to do more researches with more samples to confirm its advantages over the other membranes in bone defects around the tooth and implant surfaces.

\section{Ethics}

The authors started working on their research after the approval of the ethical board of Alexandria University on the study protocol in Egypt. The researchers followed the ethical guidelines for the care and use of ten healthy male mongrel dogs as documented by veterinarian reports in the animal house at Physiology Department, Faculty of Medicine, Alexandria University.

\section{References}

1. Nyman S, Lindhe J, Karring T, Rylander $\mathrm{H}$. New attachment following surgical treatment of human periodontal disease. J Clin Periodontol. 1982;9(4):290-6. https://doi.org/10.1111/ j.1600-051x.1982.tb02095.x 


\section{PMid:6964676}

2. Dahlin C, Sennerby L, Lekholm U, Linde A, Nyman S. Generation of new bone around titanium implants using a membrane technique: An experimental study in rabbits. Int J Oral Maxillofac Implants. 1989;4(1):19-25.

PMid:2599578

3. Buser D, Dula K, Belser U, Hirt HP, Berthold H. Localized ridge augmentation using guided bone regeneration. 1. Surgical procedure in the maxilla. Int J Periodont Rest Dent. 1993;13(1):29-45.

PMid:8330945

4. Brownfield LA, Weltman RL. Ridge preservation with or without an osteoinductive allograft: A clinical radiographic micro-computed tomography, and histologic study evaluating dimensional changes and new bone formation of the alveolar ridge. J Periodontol. 2012;83(5):581-9. https://doi.org/10.1902/ jop.2011.110365

PMid:21942791

5. El Askary AE. Fundamentals of esthetic implant dentistry. In: Immediate Esthetic Implant Therapy. $2^{\text {nd }}$ ed., Ch. 6. Munksgaard: Wiley-Blackwell Publishing; 2007. p. 179-207.

6. Donos N, Kostopoulos L, Karring T. Augmentation of the rat jaw with autogeneic cortico-cancellous bone grafts and guided tissue regeneration. Clin Oral Implants Res 2002;13(2):192202. https://doi.org/10.1034/j.1600-0501.2002.130210.x PMid:11952740

7. Aurer A, JorgiÊ-Srdjak K. Membranes for periodontal regeneration. Acta Stomat Croat. 2005;39:107-12.

8. Florjanski W, Orzeszek S, Olchowy A, Grychowska N Wieckiewicz W, Malysa A, et al. Modifications of polymeric membranes used in guided tissue and bone regeneration. Polymers. 2019;11(5):782. https://doi.org/10.3390/ polym11050782

PMid:31052482

9. Sandherg E, Dahlin C, Linate A. Bone regeneration by the osteopromotive technique using bioabsorbable membranes. An experimental study in rats. Int $\mathrm{J}$ Oral Maxillofac Surg. 1993;51(10):1106. https://doi.org/10.1016/s0278-2391(10)80450-1 PMid:8410448

10. Liu J, Kerns DG. Mechanisms of guided bone regeneration: A review. Open Dent J. 2014;8:56-65. https://doi. org/10.2174/1874210601408010056 PMid:24894890

11. Taskonak B, Ozkan Y. An alveolar bone augmentation technique to improve esthetics in anterior ceramic FPDs: A clinical report. J Prosthodont. 2006;15(1):32-6. https://doi. org/10.1111/j.1532-849X.2006.00066.x PMid:16433649

12. Barone A, Aldini N, Fini M, Giardino M, Calvo-Guirado L, Covani U. Xenograft versus extraction alone for ridge preservation after tooth removal: A clinical and histomorphometric study. J Periodontol. 2008;79(8):1370-7. https://doi.org/10.1902/jop.2008.070628 PMid: 18672985

13. De Lucca L, da Costa Marques M, Weinfeld I. Guided bone regeneration with polypropylene barrier in rabbit's calvaria: A preliminary experimental study. Heliyon. 2018;4(6):e00651. https://doi.org/10.1016/j.heliyon.2018.e00651 PMid:30003155

14. De Oliveira EL, Carvalho PS, Silva TB. Histological and histomorphometric evaluation of efficacy of a polypropylene barrier in guided bone regeneration and modified guided bone regeneration in critical defects in rodent cranial vaults. J Indian Soc Periodontol. 2019;23(4):351-5. https://doi.org/10.4103/jisp.jisp_111_18 PMid:31367133
15. Carvalho, RS, Nelson D, Kelderman H, Wise R. Guided bone regeneration to repair an osseous defect. AJODO. 2003;123(4):455-67. https://doi.org/10.1067/mod.2003.59 PMid:12695774

16. Simion M, Dahlin C, Rocchietta I, Stavropulos A, Sanchez R, Karring $T$. Vertical ridge augmentation with guided bone regeneration in association with dental implants: An experimental study in dogs. Clin Oral Impl Res. 2007;18(1):86-94. https://doi. org/10.1111/j.1600-0501.2006.01291.x PMid: 17224028

17. Schwarz F, Herten M, Ferrari D, Wieland M, Schmitz L, Engelhardt E, et al. Guided bone regeneration at dehiscencetype defects using biphasic hydroxyapatite + beta tricalcium phosphate (Bone Ceramic) or a collagen-coated natural bone mineral (BioOss Collagen): An immunohistochemical study in dogs. Int J Oral Maxillofac Surg. 2007;36(12):1198-206. https:// doi.org/10.1016/j.ijom.2007.07.014 PMid:17826958

18. AIGhamdi AS, Ciancio SG. Guided tissue regeneration membranes for periodontal regeneration-a literature review. J Int Acad Periodont. 2009;11(3):226-31.

PMid: 19753801

19. Simion M, Fontana F, Raperini G, Maiorana C. Vertical ridge augmentation by expanded-polytetrafluoroethylene membrane and a combination of intraoral autogenous graft and deproteinized anorganic bovine bone (Bio Oss). Clin Oral Impl Res. 2007;18(5):620-9. https://doi. org/10.1111/j.1600-0501.2007.01389.x PMid: 17877463

20. Schwarz F, Rothamel D, Herten M, Sager M, Ferrari D, Becker J. Immunohistochemical characterization of guided bone regeneration at dehiscence-type defect using different barrier membranes: An experimental study in dogs. Clin Oral Impl Res. 2008;19(4):40215. https://doi.org/10.1111/j.1600-0501.2007.01486.x PMid:18324961

21. Schallhorn RG, Mclain PK. Combined osseous composite grafting, root conditioning, and guided tissue regeneration. Int $\mathrm{J}$ Periodont Rest Dent. 1988;8(4):8-31. PMid:3075201

22. Anderegg CR, Martin SJ, Gray JT, Gher ME. Clinical evaluation of the use of decalcified freeze dried bone allograft with guided tissue regeneration in the treatment of molar furcation invasions. J Periodontal. 1991;62(4):264-8. https://doi.org/10.1902/ jop.1991.62.4.264

PMid:2037957

23. Caffesse R, Nasjlestic CE, Poltzke A, Anderson GB, Morrison E. GTR and bone grafts in the treatment of furcations. J Periodont. 1993;64(11 Suppl):1145-53. https://doi.org/10.1902/ jop.1993.64.11s. 1145 PMid:8295103

24. Mallado JR, Salkin LM, Fredman AL, Skin MD. A comparative study of e-PTEF periodontal membranes with and without decalcified freeze-dried bone allografts for the regenerations of interproximal intraosseous defects. $\mathrm{J}$ Periodont. 1995;66(9):751-5. https://doi.org/10.1902/jop.1995.66.9.751 PMid:7500239

25. Becker W, Lynch SE, Lekhdm U, Becker BE, Caffesse R, Donath $\mathrm{K}$, et al. A comparison of e-PTEF membranes alone or in combination with platelet derived growth factors and insulin like growth factor 1 or demineralized freeze dried bone in promotion bone formation around immediate extraction socket implants. J Periodont. 1992;63(11):929-40. https://doi.org/10.1902/ jop.1992.63.11.929

PMid:1453308 